\title{
DESINFECCIÓN DE AGUAS MEDIANTE OXÍGENO SINGLETE
}

\author{
WATER DISINFECTION BY SINGLET OXYGEN
}

\author{
Ma Emilia Jiménez Hernández
}

\begin{abstract}
RESUMEN
Esta comunicación ofrece una visión general de las investigaciones sobre los procedimientos de desinfección de agua basados en el empleo de oxígeno singlete, especie con acción bactericida que puede generarse de forma catalítica mediante fotosensibilización. La presentación comienza con una revisión de los tratamientos existentes actualmente para la desinfección del agua, destacando las ventajas y los inconvenientes o limitaciones que caracterizan a algunos de ellos. Se introducen, a continuación, las propiedades del oxígeno singlete y su reactividad hacia las moléculas que componen los sistemas biológicos, ya que en ella radica la acción germicida de esta especie reactiva de oxígeno. Una vez descrito el procedimiento de generación de oxígeno singlete mediante fotosensibilización, se muestran diversas estructuras de moléculas empleadas frecuentemente como fotosensibilizadores de oxígeno singlete. Finalmente, tras comentar algunos aspectos de las investigaciones publicadas por diversos autores sobre el empleo de oxígeno singlete como agente desinfectante, se presentan los estudios actualmente llevamos a cabo en nuestro grupo de investigación del Laboratorio de Fotoquímica Aplicada (Universidad Complutense de Madrid, España). La investigación que realizamos dentro del proyecto SOLWATER, financiado por la Unión Europea, persigue como objetivo general el desarrollo de nuevos métodos de desinfección de agua que, aprovechando la luz solar para generar la especie germicida mediante fotosensibilización, resulten económicos, seguros y respetuosos con el medio ambiente.
\end{abstract}

Palabras clave.- Desinfección de aguas, Oxigeno singlete.

\begin{abstract}
This paper provides an overview of research on water disinfection procedures based on the use of singlet oxygen, bactericidal species that can be generated catalytically by photosensitization. The presentation begins with a review of currently available treatments for water disinfection, highlighting the advantages and disadvantages or limitations that characterize some of them. Are introduced, then the properties of singlet oxygen and its reactivity to the molecules that comprise biological systems because it lies in the germicidal action of this reactive oxygen species. Having described the process of generation of singlet oxygen by photosensitization, showing various structures of molecules commonly used as singlet oxygen photosensitizers. Finally, after discussing some aspects of the research published by various authors on the use of singlet oxygen as a disinfectant, is currently present studies we conducted in our research group of the Laboratory of Applied Photochemistry (Universidad Complutense de Madrid, Spain). The research into SOLWATER project, funded by the European Union, the general had with objective of developing new methods of disinfecting water, using sunlight to generate the kind germicide by photosensitization, resulting economic, safe and friendly environment.
\end{abstract}

Keywords.- Waste disinfection, Singlet oxygen.

${ }^{1}$ Laboratorio de Fotoquímica Aplicada, Departamento de Química Orgánica, Facultad de Química Universidad Complutense Madrid, España. 


\section{INTRODUCCIÓN}

\section{TRATAMIENTOS DE DESINFECCIÓN DEL AGUA}

El agua puede ser un vehículo transportador de microorganismos causantes de enfermedades en humanos y en otros animales que suelen afectar al aparato digestivo. La mayoría de los patógenos de transmisión hídrica pertenece a uno de los siguientes cuatro grandes grupos: virus, bacterias, protozoos o helmintos (gusanos o lombrices intestinales). El uso de agua contaminada para beber o cocinar, el contacto con la misma durante baños o su inahalación en aerosoles puede resultar en infecciones.

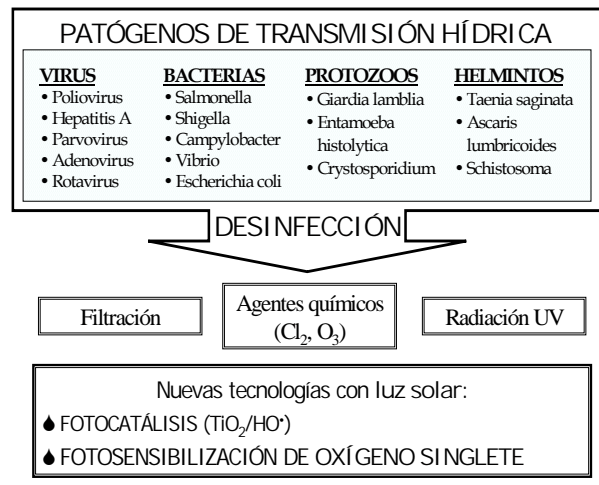

\section{Fig. 1 Ejemplos de agentes patógenos de transmisión hídrica y de métodos de desinfección.}

La escasez de agua potable es un serio problema en multitud de países y regiones. Para maximizar el aprovechamiento de los recursos hídricos puede recurrirse a la purificación del agua de desecho y su posterior reutilización. Por otra parte, en los sistemas seguros de distribución de agua para el consumo humano, el agua natural de origen superficial debe someterse a tratamientos de desinfección. Dentro del proceso de tratamiento del agua, la desinfección consiste normalmente en una operación química que tiene como objetivo la inactivación de microorganismos patógenos para minimizar así el riesgo de enfermedades. Durante los primeros 75 años del siglo $\mathrm{XX}$, los procesos de tratamiento del agua de suministro urbano se limitaban prácticamente a la clarificación química, la filtración a través de medios granulares y la cloración. En los últimos 25 años se ha producido un cambio dramático en las políticas de aprovechamiento de los recursos hídricos para el consumo humano, considerándose seriamente la necesidad de tecnologías alternativas a los tratamientos tradicionales [1].

Entre los métodos químicos de desinfección, la adición de cloro es eficaz para la inactivación de virus y bacterias; sin embargo, la formación de productos secundarios potencialmente tóxicos o cancerígenos supone un importante inconveniente. Además, la fabricación de cloro y sus derivados, así como su almacenamiento, transporte y utilización suponen un continuo riesgo para los operarios y el medioambiente. De forma similar, el ozono, uno de los agentes oxidantes más potentes entre los desinfectantes químicos, escapa del agua durante la operación de desinfección amenazando la salud de los operarios y del medioambiente a concentraciones tan bajas como $0,03 \mathrm{~g} \mathrm{~m}^{-3}$. El ozono, además, no puede almacenarse, requiere de un considerable consumo de energía para su producción y puede oxidar los iones bromuro presentes en el agua dando lugar a iones bromato tóxicos.

Se han investigado nuevas técnicas de desinfección que sustituyan estos métodos químicos por otros más saludables y respetuosos con el entorno como la filtración en membrana. A pesar del creciente desarrollo y aplicación de nuevas técnicas de filtración con membrana (micro-, ultra-, nano-filtración y ósmosis reversa), el elevado coste de esta tecnología impide su utilización a gran escala. De forma similar, la acción germicida de la luz ultravioleta presenta como inconveniente principal la imposibilidad de funcionar con luz natural (encareciéndose el proceso de desinfección), además de su incapacidad para controlar simultáneamente el color, sabor y olor debido a su carencia de poder oxidante.

Actualmente se encuentran en fase de investigación nuevas tecnologías de descontaminación y desinfección basadas en la generación fotocatalítica de especies reactivas del oxígeno, como el radical hidroxilo o el oxígeno singlete. Mediante el aprovechamiento de la luz solar estas tecnologías abren las puertas hacia el desarrollo de nuevos métodos que reúnan los requisitos de economía, seguridad, respeto al medio ambiente y autonomía. La fotocatálisis basada en la interacción de la luz con 
semiconductores sólidos como el dióxido de titanio $\left(\mathrm{TiO}_{2}\right)$, produce especies altamente oxidantes como el radical hidroxilo, que destruye tanto bacterias como una gran variedad de contaminantes químicos del agua [2, 3 y 4]. Una de las limitaciones del semiconductor $\mathrm{TiO}_{2}$, por poseer una energía interbandas de $3,2 \mathrm{eV}$ (equivalente a $387 \mathrm{~nm}$ ), es que funciona únicamente en la región UV-A, que representa menos del $1 \%$ del espectro solar.

\section{OXÍGENO SINGLETE: PROPIEDADES, REACTIVIDAD Y GENERACIÓN FOTOSENSIBILIZADA}

El oxígeno singlete es un estado excitado de la molécula de dioxígeno, y suele representarse de forma abreviada ${ }^{1} \mathrm{O}_{2}$. Presenta un exceso energético de 94,2 $\mathrm{KJ} / \mathrm{mol}$ sobre su estado fundamental de naturaleza triplete $\left({ }^{3} \mathrm{O}_{2}, \quad\right.$ o simplemente $\mathrm{O}_{2}$ ). La desactivación radiativa del oxígeno singlete a su estado fundamental va acompañada de una característica emisión de fosforescencia en la región del infrarrojo, centrada a $1270 \mathrm{~nm}$. La monitorización de esta emisión permite determinar el tiempo de vida de esta especie en distintas condiciones. En medio gaseoso pueden registrarse tiempos de vida tan largos como 15 min. En disolución acuosa presenta, sin embargo, un tiempo de vida significativamente más corto debido a la competencia de la desactivación no radiativa mediante colisiones con las moléculas del disolvente. Con un tiempo de vida del orden de microsegundos, la difusión del ${ }^{1} \mathrm{O}_{2}$ desde su fuente de generación hasta su objetivo potencial está muy restringida, con un recorrido medio en entornos acuosos de aproximadamente $100 \mathrm{~nm}$ [5].
(1) Emisión de fosforescencia

$$
\begin{aligned}
& \Rightarrow \lambda_{\text {max }}{ }^{\text {em }}=1270 \mathrm{~nm} \\
& \Rightarrow \tau_{\Delta} \text { (aire) } \leq 15 \mathrm{~min} \\
& \Rightarrow \tau_{\Delta} \text { (agua) }=3-5 \mu \mathrm{s}
\end{aligned}
$$

\section{Desactivación no radiativa}

จ Recorrido medio (agua): 0,1 $\mu \mathrm{m}$

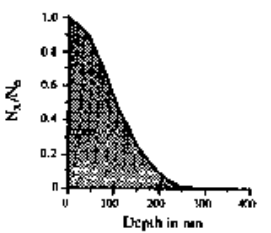

\section{(3) Reacción con biomoléculas}
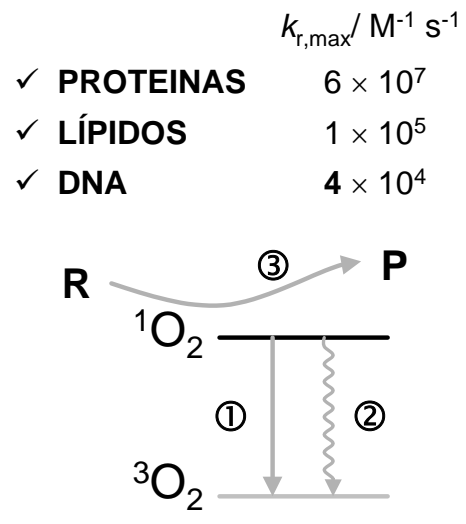

T.A. Dahl, en "Aquatic and Surface Photochemistry", CRC Press, 1994, pp 241-258.

Fig. 2 Propiedades y reactividad frente a biomoléculas del oxígeno singlete.

El oxígeno singlete puede reaccionar químicamente con diversas moléculas. En particular, dentro los cuatro grupos de compuestos constituyentes de los sistemas biológicos, únicamente los hidratos de carbono son esencialmente no reactivos frente al oxígeno singlete. Los tres restantes, proteínas, lípidos y ácidos nucleicos, presentan una significativa reactividad hacia el ${ }^{1} \mathrm{O}_{2}$ [6]. Los principales cambios químicos en péptidos y proteínas como consecuencia de su reacción con ${ }^{1} \mathrm{O}_{2}$ consisten en la destrucción de las cadenas laterales de algunos aminoácidos, como histidina y triptófano, más que la ruptura del enlace peptídico o de puentes disulfuro. La reacción característica de los lípidos es la peroxidación lipídica, mientras que en los ácidos nucleicos las modificaciones tienen lugar preferentemente sobre la base guanina. Esta especie reactiva de oxígeno es capaz de inactivar bacterias eficientemente $[7,8,9$ y 10]. Los distintos tipos celulares investigados hasta el momento, desde procariotas hasta células de mamífero, sufren daño irreversible por exposición a ${ }^{1} \mathrm{O}_{2}$ que conduce a la muerte celular $[11,12$, 13,14 y 15]. El oxígeno singlete puede generarse fotoquímicamente empleando un 
fotosensibilizador adecuado. El proceso de fotosensibilización puede describirse mediante la siguiente secuencia: el fotosensibilizador, que inicialmente se encuentra en estado fundamental singlete, por absorción de luz (ultravioleta o visible) pasa a un estado excitado singlete que, mediante un proceso de cruce entre sistemas se relaja parcialmente a un estado excitado triplete. $\mathrm{Si}$ durante el tiempo de vida del estado excitado triplete del fotosensibilizador éste colisiona con una molécula de oxígeno en estado fundamental, puede producirse una transferencia de energía entre ambas especies, resultando el oxígeno en estado excitado singlete y recuperándose el fotosensibilizador en estado fundamental.

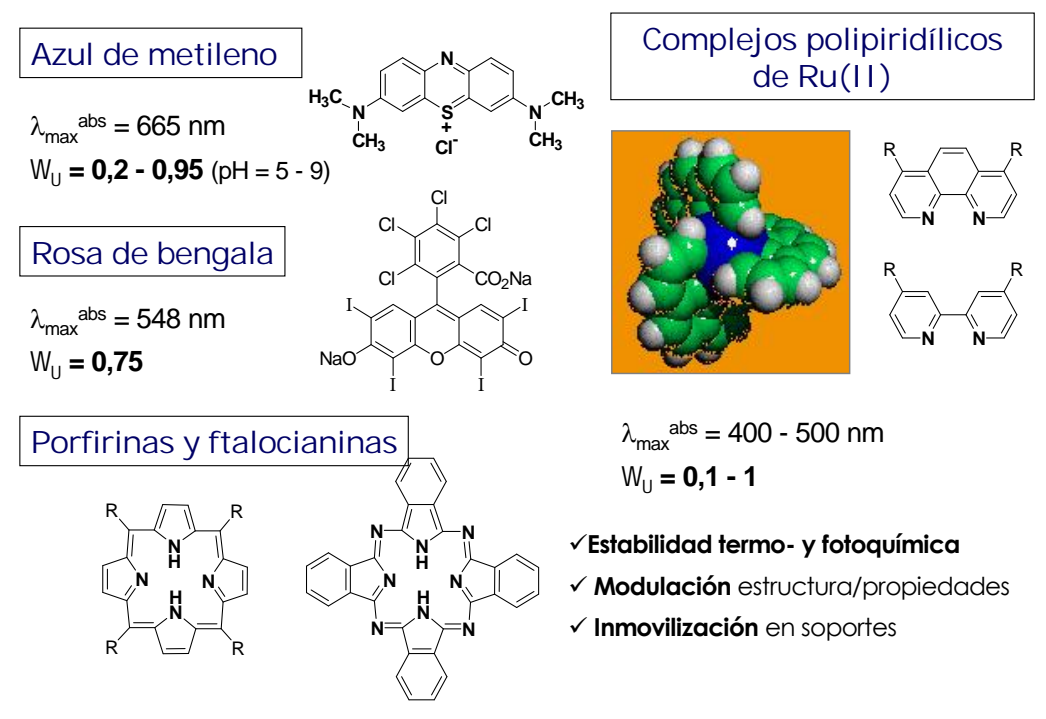

Fig. 3 Fotosensibilizadores del oxígeno singlete.

Existen numerosos colorantes, tales como el rosa de bengala, el azul de metileno o derivados de porfirinas y ftalocianinas, que absorben luz visible $y$ son capaces de generar ${ }^{1} \mathrm{O}_{2}$, mediante transferencia de energía, con buenos rendimientos cuánticos [16].

También los compuestos de coordinación del rutenio (II) con ligandos poliazaheterocíclicos quelatantes se han descrito en la bibliografía como generadores de oxígeno singlete con elevada eficiencia [17, 18 y 19]. Estos complejos metálicos exhiben, además, características únicas que los hacen muy convenientes para su empleo en la preparación de materiales fotocatalíticos para la desinfección mediante oxígeno singlete: una intensa absorción en la región visible del espectro electromagnético (típicamente hasta $600 \mathrm{~nm}$ ), estados excitados de vida suficientemente larga (típicamente de 0,05 a 6 microsegundos en disolución acuosa a temperatura ambiente), una apreciable estabilidad térmica y fotoquímica y la posibilidad de modular su carga global (positiva, nula o negativa) y sus propiedades físicas y espectroscópicas mediante la selección de los ligandos quelatantes adecuados. En dichos ligandos pueden incorporarse con relativa facilidad los grupos funcionales necesarios para permitir la incorporación del complejo metálico a soportes poliméricos hidrófobos o para lograr su unión electrostática o covalente a matrices poliméricas, si así se desea.

\section{DESINFECCIÓN DE AGUA MEDIANTE OXÍGENO SINGLETE}

Diversos autores han abordado el estudio de la acción germicida del oxígeno singlete y de su posible aplicación a la desinfección del agua. Se han llevado a cabo ensayos de desinfección a escala de laboratorio tanto en fase homogénea como en fase heterogénea.

Dichas investigaciones están permitiendo progresar hacia la optimización de las condiciones para lograr una eficiente producción de oxígeno singlete que se traduzca en una eficaz inactivación de los microorganismos. 


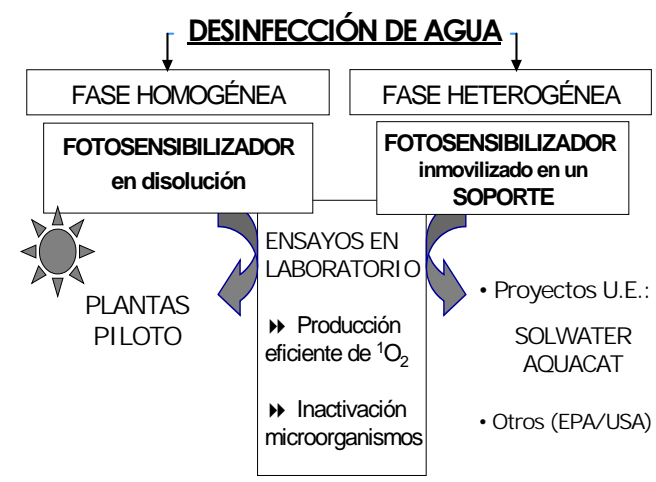

Fig. 4 Aplicación de la producción fotosensibilizada de oxígeno singlete a la desinfección del agua.

Se han descrito diversos ensayos de desinfección de agua que emplean un fotosensibilizador de oxígeno singlete disuelto en una suspensión acuosa del microorganismo contaminante. En estos ensayos se ha demostrado la efectividad de la acción fotodinámica del rosa de bengala tanto contra bacterias del tipo Gram-positivo (Deinococcus radiodurans) como contra bacterias del tipo Gram-negativo (Escherichia coli) [20 y 21]. El colorante azul de metileno se ha utilizado para la desinfección de agua en fase homogénea tanto a escala de laboratorio como en plantas piloto [22 y 23], alcanzándose disminuciones en la población microbiana de $4-5$ órdenes de magnitud en efluentes suplementados con Escherichia coli [24 y 25].

El principal inconveniente de estos tratamientos en fase homogénea es la necesidad de una complicada operación recuperación/eliminación del fotosensibilizador del agua tras concluir el tratamiento, etapa innecesaria si el proceso se lleva a cabo en fase heterogénea.

Existe ya una amplia bibliografía sobre distintas combinaciones de soportes sólidos, procedimientos de inmovilización y fotosensibilizadores para generar ${ }^{1} \mathrm{O}_{2}$ en fase heterogénea, aunque no destinados particularmente a la desinfección fotoquímica de agua. Se ha comprobado, por ejemplo, que el rosa de bengala retenido en partículas de gel de sílice soportadas en una superficie de vidrio es capaz de fotosensibilizar la producción de oxígeno singlete eficientemente $\left(5 \times 10^{12}\right.$ moléculas de ${ }^{1} \mathrm{O}_{2}$ producidas por segundo y por $\mathrm{cm}^{2}$ de soporte)
[26]. La producción de oxígeno singlete se ha demostrado en otros muchos sistemas (micro-) heterogéneos [27, 28 y 29]. Algunos estudios describen la inactivación fotodinámica de bacterias en agua llevada a cabo en fase heterogénea y que han tenido éxito a escala de laboratorio. En ellos se han empleado esferas porosas de poliestireno con rosa de bengala unido covalentemente [30], gel de sílice como adsorbente de fotosensibilizadores insolubles en agua de tipo porfirínico o metaloporfirínico [31] o poli (metacrilato de metilo) para incorporar compuestos naturales como el $\alpha$-tertienilo o derivados de porfirinas con grupos piridinio [32, 33 y 34].

El proyecto SOLWATER (http://www.psa.es/webeng/solwater/index.html) tiene como objetivo desarrollar un reactor solar que, de forma autónoma, económica y segura, permita la desinfección y descontaminación de aguas en pequeñas comunidades rurales con insuficiente infraestructura pero elevada insolación anual.

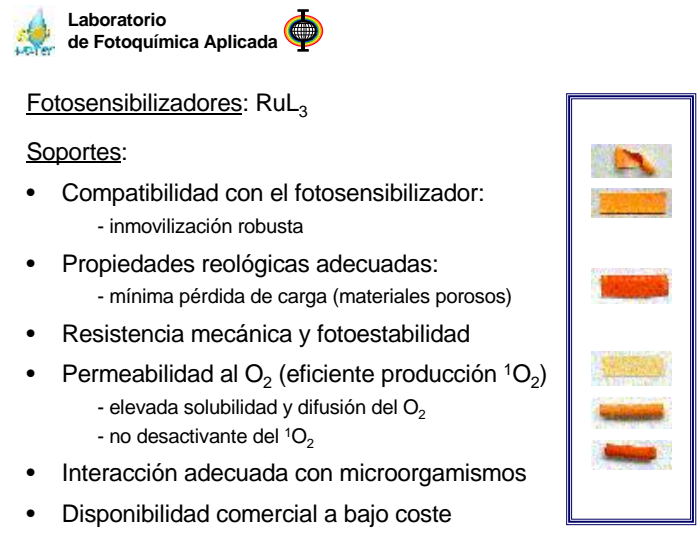

Fig. 5 Características de los sistemas fotosensibilizador-soporte seleccionados para la desinfección de agua mediante fotogenereación catalítica de oxígeno singlete.

La participación del Laboratorio de Fotoquímica Aplicada (Universidad Complutense de Madrid, España) en este proyecto se centra en el desarrollo de los materiales para llevar a cabo la desinfección mediante la producción fotosensibilizada de oxígeno singlete. Se ha optado por un procedimiento de fotosensibilización en fase heterogénea que impida la presencia del fotosensibilizador disuelto en el medio acuoso y 
permita asegurar una máxima calidad del agua tratada, ya que en este caso se destinará al consumo humano. En la fig. 5 se resumen algunas de las características deseables del soporte polimérico empleado para inmovilizar el fotosensibilizador perteneciente a la familia de los complejos polipiridílicos de rutenio (II). En la presentación se mostrarán los resultados preliminares obtenidos en relación con la preparación de estos materiales y la evaluación de su eficiencia en la desinfección de agua.

\section{REFERENCIAS}

1. Najm, I., Trussel, R. R., "New and emerging drinking water treatment technologies, en Identifying future drinking water contaminants", National Academy Press, 1999, pp. 220-246.

2. Wist, J., Sanabria, J., Dierolf, C., Torres, W., Pulgarin, C., "J. Photochem. Photobiol", A: Chem. 2002, 147, 241-246.

3. Hoffmann, M. R., Martin, S. T., Choi, W., Y., Bahnemann, D. W., "Chem. Rev". 1995, 95, 69-96.

4. Guimaraes, J. R., Ibánez, J., Litter, M. I., Pizarro, R., "Desinfección de agua en eliminación de contaminantes por fotocatálisis heterogénea", Digital Grafic, 2001, pp. 305-316.

5. Dahl, T. A., "Examining the role of singlet oxygen in photosensitized cytotoxicity, en Aquatic and Surface Photochemistry", CRC Press, 1994; pp. 241-258.

6. Kruk, I., "Environmental toxicology and chemistry of oxygen species" en The Handbook of Environmental Chemistry, Springer, 1998, Vol. 2, Part 1, pp. 89-138.

7. Acher, A. J., Fischer, E., Zellingher, R., Manor, Y., "Wat. Res”. 1990, 24, 837-843.

8. Dahl, T. A., Midden, W. R., Hartman, P. E., "Photochem. Photobiol". 1987, 46, 345352.

9. Bezman, S. A., Burtis, P. A., Izod, T. P. J., Thayer, M. A., "Photochem. Photobiol". 1978, 28, 325-329.

10. Savino, A., Angeli, G., Wat. Res. 1985, 19, 1465-1469.

11. Dahl, T. A., Photochem. Photobiol. 1991, 53, 119S.

12. Tuite, E. M., Kelly, J. M., "J. Photochem. Photobio". B. Biol. 1993, 21, 103.
13. Nagano, T., Tanaka, T., Mizuki, H., Hirobe, M., "Chem. Pharm. Bull" 1994, 42, 883-887.

14. Ben-Hur, E., Geacintov, N. E., Studamire, B., Kenney, M. E., Horowitz, B., "Photochem. Photobiol". 1995, 61, 190-195.

15. Shimizu-Takahama, M., Egashira, T., Takahama, U., "Photochem. Photobiol". 1981, 33, 689-94).

16. Wilkinson, F., Helman, W. P., Ross, A. B., "J. Phys". Chem. Ref. Data 1993, 22, 113262).

17. García-Fresnadillo, D., Georgiadou, Y., Orellana, G. Braun, A. M., Oliveros, E., "Helv. Chim". Acta 1996, 79, 1222-1238.

18. Zhang, X., Rodgers, M. A. J., "J. Phys. Chem". 1995, 99, 12797-12803.

19. Bourdelande, J. L., Font, J., Marques, G., Abdel-Shafi, A. A., Wilkinson, F., Worrall, D. R., "J. Photochem. Photobiol". A. 2001, 138, 65-68).

20. Schafer, M., Schmitz, C., Facius, R., G., Horneck, B., Milow, K.-H., Funken, J., Ortner, Photochem. Photobiol. 2000, 71, 514523.

21. Schäfer, M., Schmitz C., Horneck, G., "Int, J. Radiat". Biol. 1998, 74, 249-253.

22. Eisenberg, T. N., Middlebrooks, E. J., Adams, V. D., "Water Sci". Tech. 1987, 19, 1255-1258.

23. Acher, A. J., Fischer, E., Zellingher, R., Manor, Y., "Wat. Res". 1990, 24, 837-843.

24. Acher, A. J., Juven, B. J., "Appl. Environ. Microbiol". 1977, 33, 1019-1022.

25. Acher, A., Fischer, E., Turnheim, R., Manor, Y., Water Res. 1997, 31, 1398-1404.

26. Krishna, C. M., Lion, Y., Riesz, P., "Photochem. Photobiol". 1987, 45, 1-6.

27. Nowakowska, M., Kepczynski, M., Dabrowska, M., "Macromol. Chem. Phys". 2001, 202, 1679-1688.

28. Faust, D., Funken, K.-H., Horneck, G., Milow, B., Ortner, J., Sattlegger, M., Schafer, M., Schmitz, C., "Sol. Energy", 1999, 65, 71-74.

29. Van Laar, F. M. P. R., Holsteyns, F., Vankelecom, I. F. J., Smeets, S., Dehaen, W., Jacobs, P. A., "J. Photochem. Photobiol", A: Chemistry 2001, 144, 141-151.

30. Bezman, S. A., Burtis, P. A., Izod, T. P. J., Thayer, M. A., "Photochem. Photobiol". 1978, 28, 325-329. 
31. Mosinger, J., Losinska, K., Abrhamova, T., Veiserova, S., Micka, Z., Nemcova, I., Mosinger, B., "Anal. Lett". 2000, 33, 10911104.

32. Lin, Q., Tsuchido, T., Takano, M., “Appl. Microbiol. Biotechnol". 1991, 35, 585-590.

33. Faust, D., Funken, K.-H., Horneck, G., Milow, B., Ortner, J., Sattlegger, M.,
Schäfer, M., Schmitz, C., "Solar Energy", 1999, 65, 71-74.

34. Funken, K.-H., Faust, D., Ortner, J., Sattler, C., "Patente Europea EP984041".

Correspondencia: emi@solea.quim.ucm.es 